\title{
INTER-ANNUAL HEIGHT VARIATIONS OBSERVED BY GPS MEASUREMENTS IN TURKEY
}

\author{
Gokhan GURBUZ ${ }^{1 *}$, Shuanggen JIN ${ }^{1,2}$ \\ ${ }^{1}$ Department of Geomatics Engineering, Bulent Ecevit University, Zonguldak, 67100, Turkey - gokhan.gurbuz@beun.edu.tr \\ ${ }^{2}$ Shanghai Astronomical Observatory, Chinese Academy of Sciences, Shanghai 200030, China - sgjin@shao.ac.cn
}

KEY WORDS: Inter-annual signal, Height, GPS, Climate change

\begin{abstract}
:
Turkey is located in Africa-Eurasia-Saudi Arabian plate converged areas with surrounding by the Black Sea and the Mediterranean Sea. Apart from its tectonic conditions, the climate is complexly varying according to regions. As an example while in the northern regions floods often endanger human life, and in the middle regions, drought is a serious situation. To understand the Earth system and its temporal changes, a reliable measurement of various geophysical processes and mass redistribution is needed, which are mostly related to the regional water cycle and coupling processes associated with a mass exchange between the oceans, the lands and the atmosphere at seasonal and inter-annual timescales. Nowadays, dense and continuous GPS (Global Positioning System) observations provide direct measurements to capture such signals. In this paper, continuous GPS coordinate time series and interannual height variations are obtained and investigated from Turkish CORS network called TUSAGA-Active with more than 140 stations from 01 Jan. 2010 to 01 Jan. 2016 processed by GAMIT/GLOBK software. Results show significant inter-annual variations of GPS height time series with a period of about 2.8 years at most GPS stations. Furthermore, some relationship between interannual height and rainfall as well as ENSO index will be further investigated, indicating that inter-annual height variations are mostly related to climate changes, such as drought. These results will contribute to understand continuous GPS measurement signals in Turkey as well as applications in near-real-time geohazards estimations.
\end{abstract}

\section{INTRODUCTION}

Global Positioning System (GPS) has great advances in measurement precision and accuracy, as well as temporal resolution with wide applications in the past two decades. For example, GPS measurements have been successfully used to monitor and study Earth's surface deformation due to geophysical loadings, tectonic plate motions, glacial isostatic adjustment, earthquake, volcano, landslide and human-made activities. To understand the Earth system and its temporal changes, a reliable measurement of various geophysical processes and mass redistribution is needed. At the global scale, water cycle comprises the most significant processes associated with a mass exchange between the oceans, the lands and the atmosphere at seasonal and inter-annual timescales. In addition, air mass redistribution in the atmosphere, characterized by pressure changes, plays an important role.

Turkey is comprised of microplates, island arcs, continental blocks and accretionary prisms (Moix et al. 2008) and characterized by various compressional and extensional strains (Tan et al. 2008). The collision Turkey between Africa, Arabian and Eurasian plates has complex strain systems and frequent earthquakes, which produce a wide range of tectonic deformations (Şengör et al. 2008). Mass redistribution and transport in the Earth system, including the atmosphere, hydrosphere, lithosphere, cryosphere and the interior of the solid Earth affect the Earth's shape. Continuous space geodetic observations, particularly Global Positioning System (GPS), are capable of measuring and monitoring such small changes with high accuracy and spatial-temporal resolution. The Turkish CORS Network with about 140 stations established in 2009 provides a good chance to continuously monitor crustal deformation in Turkey. On one hand, seasonal motion from continuous GPS observations can know the error source of GPS coordinate time series and improve the accuracy of GPS positioning.

GPS processing strategies and models also affect GPS coordinate estimation. For instance, Jin et al., (2005) developed a new stochastic model to process short to medium length baselines. Results show that accuracy of GPS positioning results can be improved to the millimeter level. Zhang et al. (1997) studied the GPS array coordinate time series of Southern California for two years and was still unable to analyse the effect of flicker noise and random walk noise due to a short time series. Blewitt and Lavallee (2002) analysed the effect of annual signals on geodetic velocity in detail. All their analyses showed that geodetic coordinate time series have greater noise. For example, initial numerical experiments have shown that unrealistic stochastic models may lead to errors of up to 10-15 millimetres in height components (Howind et al., 1999, Wang et al., 2002); and noises (white noise and coloured noise) that introduce large temporal correlations into the data degrade the accuracy of geodetic measurements (Blewitt and Lavallee, 2002). In addition, the Earth is a dynamic system change over time, the system redistributes the material quality (including the Earth's interior movement, atmospheric motion, rebounded after the ice, water recycling, etc.) will lead to changes at different scales of Earth's gravitational field. Steady-state mass distribution which determines the average gravity field information, usually with a variety of Earth's gravity field model representation; rather steady part of the performance of timevarying gravity field information. Water, air quality, and land are mainly caused by seasonal changes in the gravitational field. On a longer timescale, causing Earth's mass migration process is 
very complex, involving a process of solid geophysics and geodynamics. In the long-term seasonal to load mass scale migration of the Earth's surface, including the atmosphere, oceans, and terrestrial water cycle, reflecting surface melting glaciers, rising sea levels, the quality of the atmosphere, such as migration and the global water cycle information, and is closely related to climate change.

Dong et al. (1996) pointed out, such as water, land, atmosphere, and oceans can be explained by the GPS residual time series about annual GPS amplitude of $66 \%$. However, part of remaining seasonal GPS variations are still not known. Furthermore, these studies were based on semi-empirical model geophysics assimilation models due to the lack of measured data. Especially hydrological model, due to its large observation difficult and in many areas, there is no observational data, and therefore cannot get high precision hydrological model. While seasonal GPS variations are still unknown in Turkey continent. The primary tidal displacements due to the body tides (SolidEarth tides) can reach as high as several hundred millimetres $(\mathrm{mm})$. A secondary, and indirect, set of tidal displacement signals comes from the mass loading of the ocean tides, or ocean tidal loading (OTL). Uncertainties in the OTL predictions come from those of the input ocean tide model and the a priori Earth model, as well as coastal geography and the numerical convolution scheme of the loading computation, the largest of which resides in the ocean tide model. Thirdly, loading of the Earth's crust due to variations of global atmospheric pressure can displace the positions of geodetic sites by more than $1 \mathrm{~cm}$ both vertically and horizontally on annual to sub-diurnal time scales (Zhang et al, 2012). Especially changes in the atmospheric pressure account for up to \%24 of the total variance in the GPS height estimates (van Dam, et al., 1994).

\section{DATA AND METHOD}

Data belong to these 146 GPS stations have been obtained with the permission of General Command of Mapping (Turkish National Mapping Agency) by Bulent Ecevit University, Department of Geomatics Engineering. The data starts from 2009 and it continues to upload daily observations to TUSAGA - Active system's FTP site. These data will be analysed along with 20 nearby IGS stations with GAMIT/GLOBK software (Herring et al., 2010). GAMIT/GLOBK is a comprehensive GPS analysis package developed at MIT, the HarvardSmithsonian Center for Astrophysics (CfA), Scripps Institution of Oceanography (SIO), and Australian National University for estimating station coordinates and velocities, stochastic or functional representations of post-seismic deformation, atmospheric delays, satellite orbits, and Earth orientation parameters.

The IGS orbits and Earth Rotation Parameters (ERP) will be used as prior information when starting with the Receiver Independent Exchange Format (RINEX) observation data. Then the IERS conventions 2003 are generally implemented provided by IERS conventions center. After some pre-processing steps like clock synchronization and cycle slip correction, the outlier and bad observations will be detected during the processing and automatically excluded. The updated model, FES2004, is recommended for station displacements due to ocean tidal loading at Turkey (Gurbuz and Jin, 2016). At the same time, non-tidal loading displacement should also be applied to station positions. For the troposphere propagation delays, some updated models are used to provide a better estimate (Table 1).

\begin{tabular}{|l|l|}
\hline Parameter & Value \\
\hline Choice of Experiment & Baseline \\
\hline Interval Zenith Delay & Hourly \\
\hline Elevation cut-off angle & 10 degree \\
\hline Dry and wet mapping function & VMF1, GMF, NMF \\
\hline Orbit & IGS-Final \\
\hline Ocean Tide & FES2004 \\
\hline Atmospheric Tide & Atmdisp (CM Frame) \\
\hline Solid Earth Tide & IERS \\
\hline
\end{tabular}

Table 1. Processing parameters of GAMIT/GLOBK (Gurbuz et al, 2015).

\subsection{Data Editing}

An outlier is an observation that appears to deviate markedly from other observations in the sample. Identification of potential outliers is important for the following reasons. An outlier may indicate bad data. For example, the data may have been coded incorrectly or an experiment may not have been run correctly. If it can be determined that an outlying point is, in fact, erroneous, then the outlying value should be deleted from the analysis (or corrected if possible). In some cases, it may not be possible to determine if an outlying point is bad data. Outliers may be due to random variation or may indicate something scientifically interesting. In any event, we typically do not want to simply delete the outlying observation. However, if the data contains significant outliers, we may need to consider the use of robust statistical techniques (Figure 1).
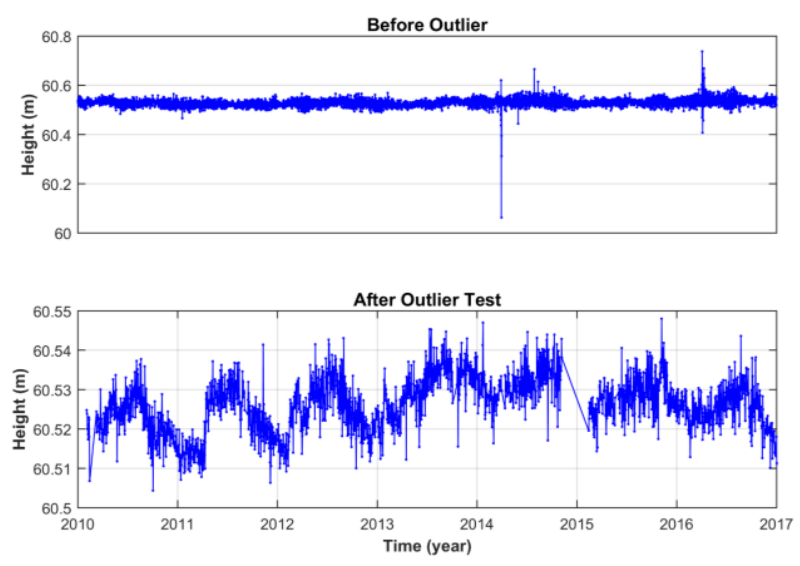

Figure 1. Outlier test on MATLAB software using sigma for ADAN station

\subsection{Seasonal Analysis}

Further analyses are made to understand phase, amplitude, and trend of height time series that are obtained from GPS measurements using following harmonic function (Jin et al, 2005).

$x_{i}=x_{0}+v t_{i}+\sum_{j} a_{j} \sin \left(2 \pi f_{j} t_{i}+\phi_{j}\right)+\ldots+\varepsilon_{x}\left(t_{i}\right)$ 
where $\mathrm{t}$ is the time (days), $\mathrm{t}_{0}$ is Jan. 1, 2010, a is the constant term, $\mathrm{b}$ is the trend term, $\mathrm{S}_{\mathrm{i}}, \mathrm{p}_{\mathrm{i}}, \varphi_{\mathrm{i}}$ are the amplitude, period, and phase at periods ( $\mathrm{i}=1$ year and 0.5 year), respectively, and $\varepsilon_{\mathrm{t}}$ is the residual. Using the least squares method, the annual and semi-annual amplitudes, phases, and uncertainties of the GPSestimated heights are determined (Gurbuz and Jin, 2017).

\section{RESULTS AND ANALYSIS}

Nearly 250 different processing is done to obtain 6 hourly and daily coordinates of more than 170 GPS stations using 7 subnetworks with same reference stations over Turkey. After data editing of the results, the seasonal analysis is carried out. Obtained results showed strong annual and semi-annual signal (Table 2). Velocities of each component computed and plotted. In Figure, 2 velocities belong to vertical components. In the first phase of evaluations, 6 hourly coordinates are analysed.

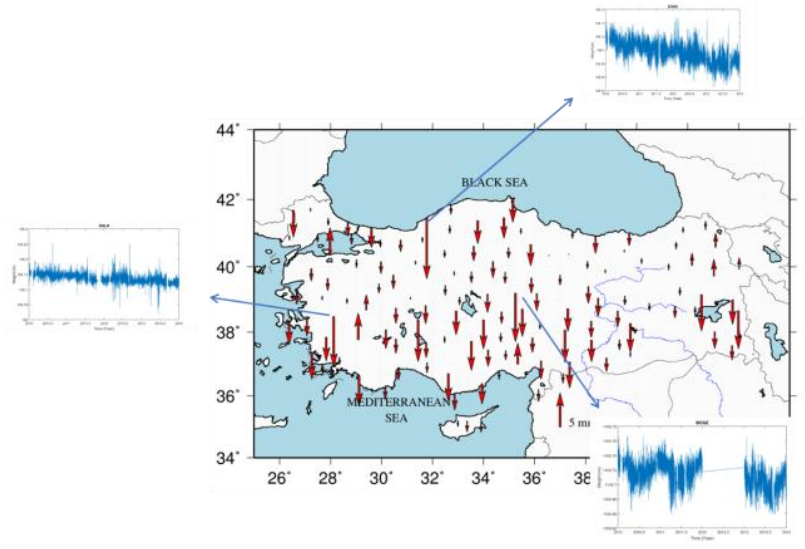

Figure 2. Vertical component velocities and time series of selected stations.

However, it is seen that in the semi-annual signal of 6 hourly coordinates have too much noise when compared to daily coordinate estimations. Therefore, in the second phase of evaluations, daily coordinates are used. As an example, in Zonguldak city the negative velocity is proven by several studies related with subsidence due to mining operations and also in Konya city, negative velocity of vertical component is proven by studies related with sinkholes incident happening occasionally.

In addition to these facts, if inspected further, one can see the fluctuation between velocities follows the fault lines called Northern Anatolian Fault (NAF) and Eastern Anatolian Fault (EAF) (Figure 3). In the second strategy for this study daily coordinates are estimated. Like in the 6 hourly coordinates, for each component of coordinates (east, north, up), the seasonal analysis is carried out. In daily coordinates, we also investigated seasonal behaviors of GPS stations and strong seasonal signals are found (Table 2).

\begin{tabular}{|l|l|l|l|l|l|}
\hline Station & $\begin{array}{c}\text { Trend } \\
(\mathrm{m} / \text { year })\end{array}$ & $\begin{array}{c}\text { Phase 1 } \\
\left({ }^{\circ}\right)\end{array}$ & $\begin{array}{c}\text { Phase 2 } \\
\left({ }^{\circ}\right)\end{array}$ & $\begin{array}{c}\text { Amp 1 } \\
(\mathrm{m})\end{array}$ & $\begin{array}{c}\text { Amp 2 } \\
(\mathrm{m})\end{array}$ \\
\hline ADAN & 0.0008 & 202.432 & 157.013 & 0.0048 & 0.0003 \\
\hline ADIY & -0.0002 & 215.576 & 289.413 & 0.0050 & 0.0004 \\
\hline AFYN & 0.0001 & 247.114 & 36.042 & 0.0030 & 0.0005 \\
\hline AGRD & 0.0022 & 214.056 & 165.077 & 0.0042 & 0.0008 \\
\hline AKDG & -0.0004 & 228.837 & 126.151 & 0.0043 & 0.0006 \\
\hline AKHR & -0.0051 & 198.319 & 91.340 & 0.0030 & 0.0008 \\
\hline AKSI & -0.0020 & 206.345 & 93.760 & 0.0057 & 0.0007 \\
\hline AKSR & -0.0031 & 225.962 & 144.650 & 0.0028 & 0.0004 \\
\hline AMAS & 0.0002 & 235.538 & 70.094 & 0.0032 & 0.0006 \\
\hline ANMU & -0.0012 & 184.629 & 241.051 & 0.0034 & 0.0003 \\
\hline ANRK & -0.0005 & 180.469 & 339.362 & 0.0033 & 0.0009 \\
\hline ANTE & -0.0014 & 217.617 & 282.021 & 0.0046 & 0.0006 \\
\hline
\end{tabular}

Table 2. Seasonal analysis results of daily coordinates.

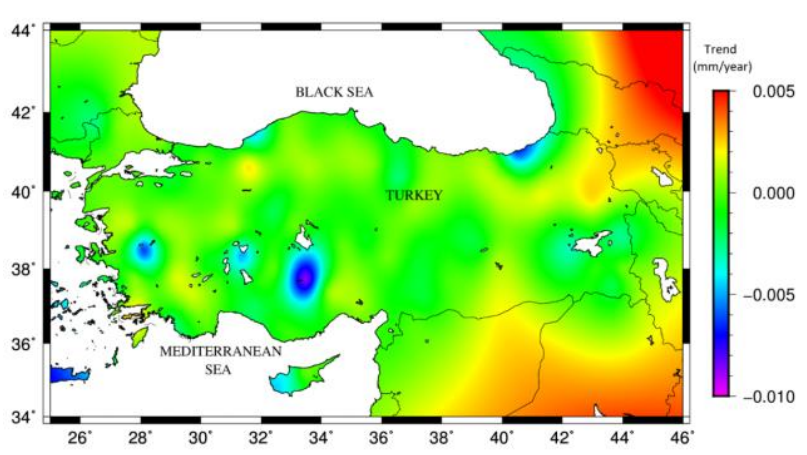

Figure 3. Vertical component of daily coordinate velocities and time series of selected sites.

Each stations time series are inspected properly and for height component, seasonal signals are plotted. As an example of this MRSI station's time series can be seen in Figure 4.
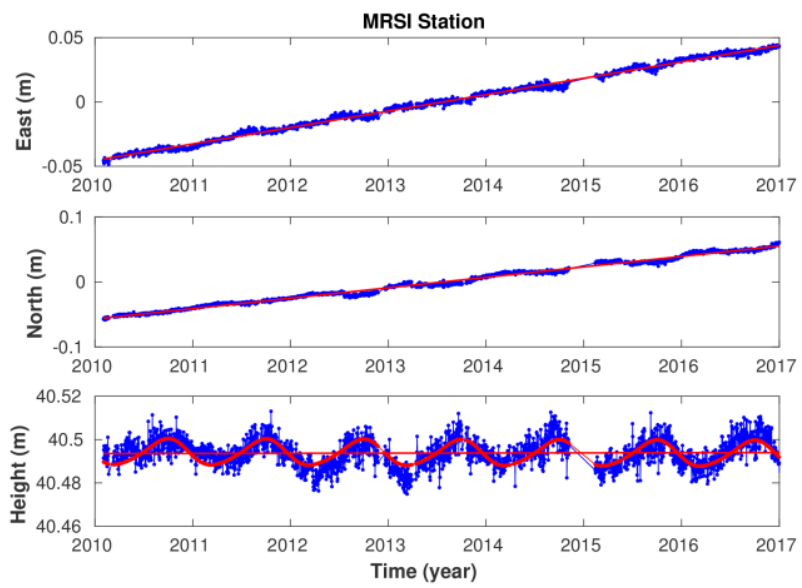

Figure 4. GPS coordinate time series at MRSI station obtained from daily coordinates. 
As for spectral analysis, CATS software is used (Williams, 2008). CATS is a free software package that allows easy and powerful manipulation of time series data in *. cats file format including cycles analysis and various multivariate mathematical techniques. It is suitable for developing economic and other models, for finding cycles in time series and for forecasting. In the Fourier analysis fluctuations observed in the frequency domain. In Figure 5, vertical axes represent amplitude while horizontal axes represent the cycle of the frequency of MRSI station.

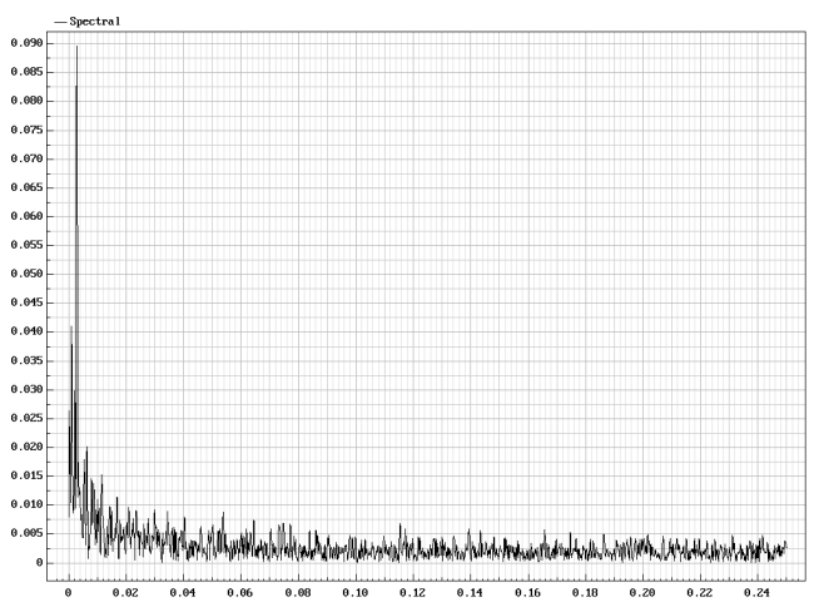

Figure 5. Spectral analysis of MRSI station (CATS software)

Also in Figure 6 one of the CATS software output shown. Each row shows one cycle period peak from the spectrum. The first column is the number of cycles present in the entire period. The second column is the period in the units of the folder being used, in this case in months. The next two columns are the correlations with sine and cosine waves and the combined amplitudes of these is shown in the fifth column. A larger amplitude means that the cycle is stronger, however long cycles usually have large amplitudes and short cycles have smaller amplitudes. The last column is the Bartel statistic which is the probability of the cycle arising from pure chance (Bartel, 1932). The values marked in pink are likely to be real cycles, especially the last two.

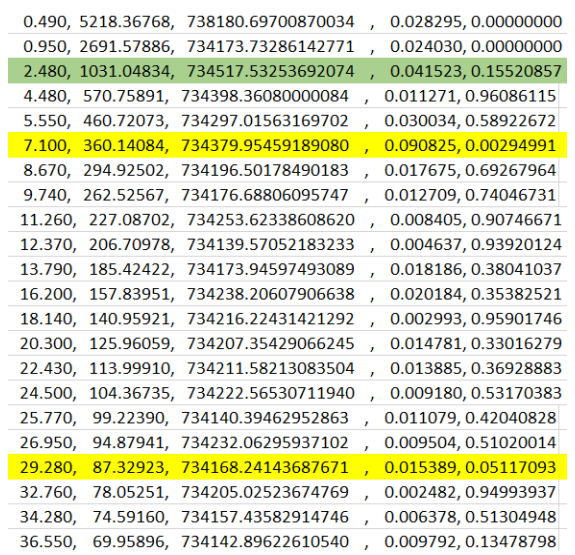

Figure 6. The output of spectral analysis from CATS software.

The annual signal is also can be seen Figure 7, to prove this inter-annual signal, seasonal component is removed from the main signal.
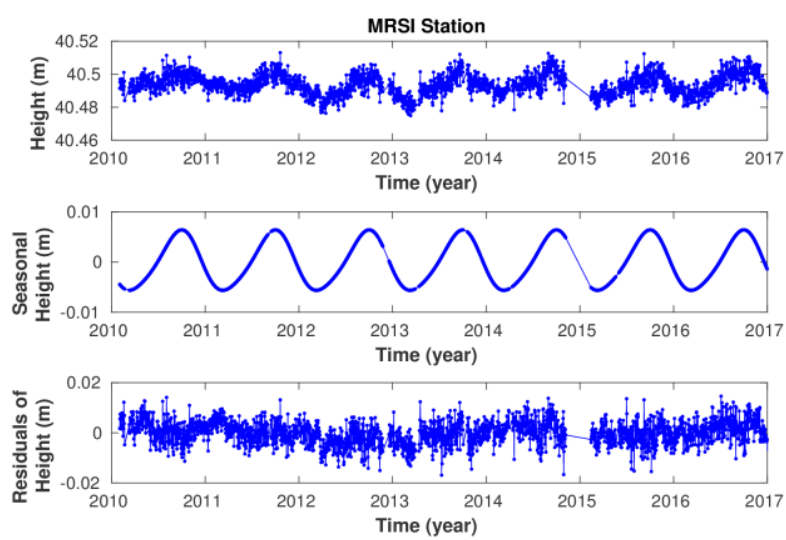

Figure 7. Seasonal component of MRSI station.

After removal of the annual signal, Fast Fourier Transformation applied to the data and inter-annual signal showed itself. In Figure 7, annual signal removal can be seen for MRSI station. This also seen at selected ten stations. This means the interannual signal is true and should be furthermore investigated (Figure 8).

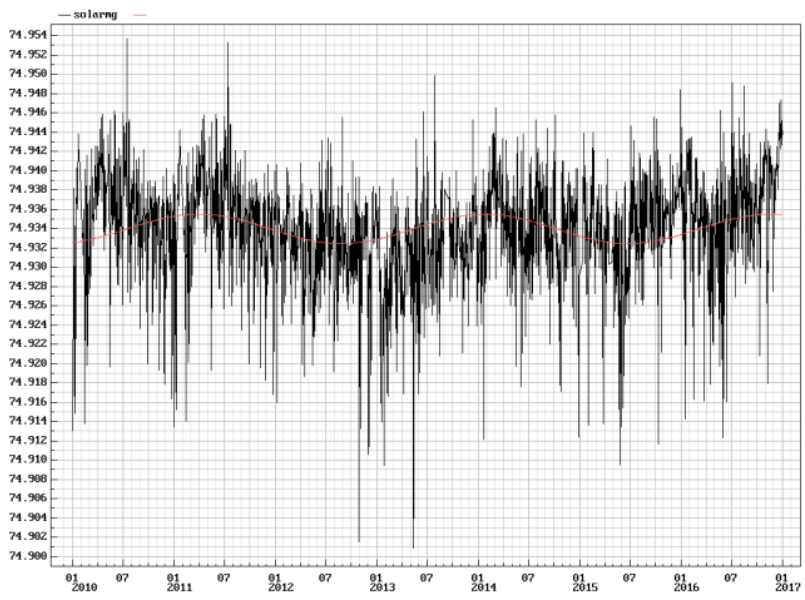

Figure 8. Inter-annual signal of MRSI station.

After annual signal removed, the strong inter-annual signal is seen on the stations. This inter-annual signal consists of 2.8-2.9 year of the cycle at all the stations. Figure 9 also shows nonseasonal height component and inter-annual signal it contains.
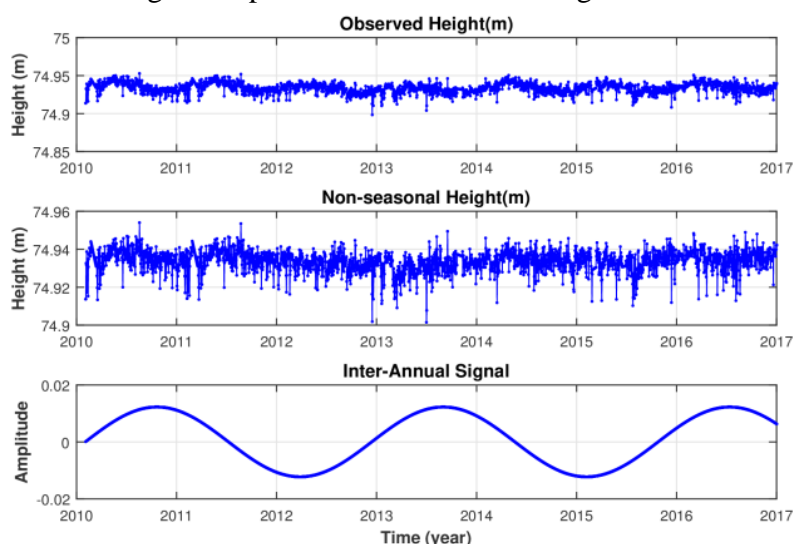

Figure 9. The inter-annual signal of MRSI station. 


\section{CONCLUSION}

Preliminary results regarding 6 hourly and daily coordinates were obtained from 7 years of GPS observations. This process took one and a half year with more than 250 processing. After processing finished data editing is carried out and outlier test used on Matlab software using sigma. Apart from outlier test, several stations excluded from evaluations and further investigations due to lack of long-time observations. These excluded stations include stations effected from earthquakes and changes on the stations antenna and locations. After data editing finished time series plotted and investigated anomalies.

Seasonal behaviors of GPS sites were investigated, strong seasonal and inter-annual signals were found all of the stations. While most stations have close phase values for height component, their amplitudes vary with $3-8 \mathrm{~mm}$. After carefully inspection to 6 hourly height components, it is clearly seen that semi-annual signals have too much noise. Therefore, after this point, daily data is used for further investigations. As for spectral analysis, CATS software is used. CATS is a free software package that allows easy and powerful manipulation of time series data in *. cats file format including cycles analysis and various multivariate mathematical techniques. It is suitable for developing economic and other models, for finding cycles in time series and for forecasting. In the Fourier analysis fluctuations observed in the frequency domain. To obtain nonlinear trends, seasonal signals (annual and semi-annual) removed from time series. After removal of annual and semiannual components, a strong inter-annual signal found at all tested stations.

For the future plans, temperature, rainfall data and oscillation data will be compared with the height component time series to investigate the connection between climate change and height time series.

\section{ACKNOWLEDGEMENTS (OPTIONAL)}

The study was partially performed at TUBITAK ULAKBIM, High Performance and Grid Computing Center (TRUBA resources). The authors are grateful to the organizations that provided the data, including General Command of Mapping (HGK) for TUSAGA-Active data.

\section{REFERENCES}

Bartels, J. 1932. Statistical methods for research on diurnal variations. Journal of Geophysical Research, 37(3), pp. 291302.

Blewitt, G., \& Lavallée, D. 2002. Effect of annual signals on geodetic velocity. Journal of Geophysical Research: Solid Earth, 107(B7).

Dong, D., Gross, R. S., \& Dickey, J. O. 1996. Seasonal variations of the Earth's gravitational field: An analysis of atmospheric pressure, ocean tidal, and surface water excitation. Geophysical Research Letters, 23(7), pp. 725-728.

Gurbuz, G., Jin, S., \& Mekik, C. 2015. Sensing Precipitable Water Vapor (PWV) using GPS in Turkey-Validation and Variations. In Satellite Positioning-Methods, Models and Applications. InTech.

Gokhan, G., \& Jin, S. 2016. Evaluation of ocean tide loading effects on GPS-estimated precipitable water vapour in Turkey. Geodesy and Geodynamics, 7(1), pp. 32-38.
Gurbuz, G., \& Jin, S. 2017. Long-time variations of precipitable water vapour estimated from GPS, MODIS and radiosonde observations in Turkey. International Journal of Climatology, 37(15), pp. 5170-5180.

Herring, T.A., King, R.W., McClusky, S.C., 2010. GAMIT Reference Manual Reference Manual GPS Analysis at MIT. Department of Earth, Atmospheric, and Planetary Sciences Institute of Technology, Massachusetts.

Howind, J., Kutterer, H., \& Heck, B. 1999. Impact of temporal correlations on GPS-derived relative point positions. Journal of Geodesy, 73(5), pp. 246-258.

Jin, S., Wang, J., \& Park, P. H. 2005. An improvement of GPS height estimations: stochastic modeling. Earth, planets and space, 57(4), pp. 253-259.

Moix, P., Beccaletto, L., Kozur, H. W., Hochard, C., Rosselet, F., \& Stampfli, G. M. 2008. A new classification of the Turkish terranes and sutures and its implication for the paleotectonic history of the region. Tectonophysics, 451(1-4), pp. 7-39.

Şengör, A. C., Özeren, M. S., Keskin, M., Sakınç, M., Özbakır, A. D., \& Kayan, I. 2008. Eastern Turkish high plateau as a small Turkic-type orogen: Implications for post-collisional crust-forming processes in Turkic-type orogens. Earth-Science Reviews, 90(1-2), pp. 1-48.

van Dam, T. M., Blewitt, G., \& Heflin, M. B. 1994. Atmospheric pressure loading effects on Global Positioning System coordinate determinations. Journal of Geophysical Research: Solid Earth, 99(B12), pp. 23939-23950.

Wang, X. Y., Zhu, W. Y., Fu, Y., You, X. Z., Wang, Q., Cheng, Z. Y., \& Ren, J. W. 2002. Present-Time Crustal Deformation in China and its Surrounding Regions by GPS. Chinese Journal of Geophysics, 45(2), pp. 195-208.

Williams, S. D. 2008. CATS: GPS coordinate time series analysis software. GPS solutions, 12(2), pp. 147-153.

Zhang, Y., Wallace, J. M., \& Battisti, D. S. 1997. ENSO-like interdecadal variability: 1900-93. Journal of climate, 10(5), pp. 1004-1020.

Zhang, L.J., S.G. Jin, and T.Y. Zhang 2012. Seasonal variations of Earth's surface loading deformation estimated from GPS and satellite gravimetry. J. Geod. Geodyn., 32(2), pp. 32-38. 